\title{
PREPARATION AND EVALUATION OF NAPROXEN ADSORBATE AS AN ATTEMPT TO IMPROVE DRUG DISSOLUTION CHARACTERISTICS
}

\author{
Ahmed Ismail, K. I. Saleh and S. Khalaf \\ Department of Pharmaceutics, Faculty of Pharmacy, Al-Azhar University at Assiut, Assiut, \\ Egypt

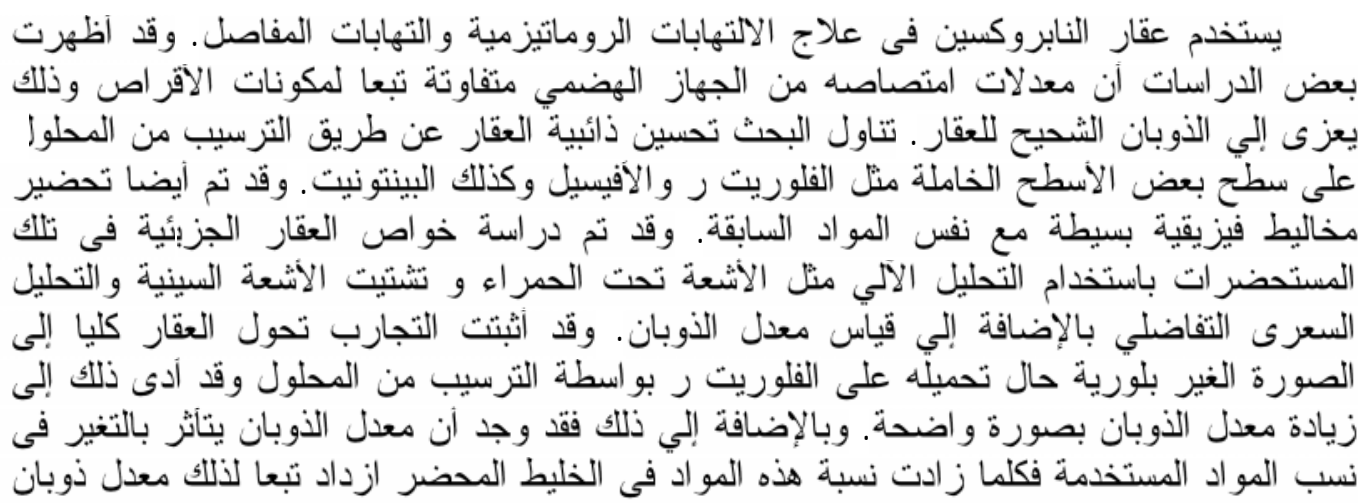

Naproxen is a nonsteroidal anti-inflammatory drug which shows variable absorption and bioavailability due to its poor solubility. In this study we aimed to improve the dissolution rate of the drug by solvent deposition onto certain adsorbents including porous silica, Avicel and Bentonite. Physical mixtures of naproxen with the investigated adsorbents were also prepared. The molecular behavior of naproxen in the investigated systems were studied using infrared absorption spectra, differential scanning calorimetry and X-ray diffraction analysis. The dissolution rate of the drug was also investigated. The obtained results indicated that naproxen was transformed to the amorphous state in case of mixtures loaded with porous silica. This transformation resulted in a significant enhancement of the dissolution rates of the drug. In addition, it was noticed that, the drug: adsorbents weight ratio of the prepared mixtures influenced the drug dissolution rate enhancement. Accordingly, it can be concluded that, by increasing the weight ratio of the used adsorbent in the mixture, the larger the enhancement in the dissolution rate of naproxen will be obtained.

\section{INTRODUCTION}

For relatively insoluble drugs, the rate of dissolution is usually the rate determining step in the overall absorption process. Reduction of the particle size remains the accepted method for increasing dissolution rate. ${ }^{1}$

Naproxen is a member of nonsteroidal anti-inflammatory drugs which exhibits poor solubility in water. This undesirable physical property may increase the incidence of its irritating side effect on the gastrointestinal tract because of prolonged contact time with the mucosa.
Several techniques have been successfully adopted to improve the dissolution rate of these drugs including solid dispersions with various carriers, ${ }^{2-5}$ solid solutions, ${ }^{6}$ co-grinding with certain carriers, ${ }^{7}$ surface hydrophilization ${ }^{8}$ and also inclusion complexation with $\beta$ cyclodextrin and its derivatives has been reported to enhance the dissolution characteristics of a variety of poorly soluble drugs. ${ }^{9-12}$

Surface adsorption is one of the methods used to reduce the particle size by increasing the surface area available to the dissolution medium. ${ }^{13}$ The technique of the surface 
adsorption was first reported by Mankhouse and Lach. This technique has been employed to improve the dissolution characteristics of poorly water soluble drugs. ${ }^{14}$

Among the mostly used adsorbents are veegum, ${ }^{15}$ Bentonite, ${ }^{16}$ microcrystalline cellulose, ${ }^{17}$ some disintegerants ${ }^{18}$ and silicates as Florite.

Florite (porous calcium silicates) is widely used as a drug carrier in pharmaceutical preparations for its excellent flowability, mouldability. Moreover, it has a pure synthetic inorganic unabsorbable material so that it is considered safe for oral administration. ${ }^{17}$ Molecular dispersion of drug onto the extremely large surface area of porous silica have been utilized for improving dissolution rates and absorption of several poorly water soluble drugs. ${ }^{19}$

\section{EXPERIMENTAL}

\section{Materials and methods \\ Materials}

Naproxen (Misr Pharmaceutical Co., Egypt), Porous calcium silicate (Florite R) (Tokoyama Soda Co., Japan), Microcrystalline cellulose (Avicel PH 101) (FMC Co., Ireland), Bentonite, (Nile Co. for Pharmaceutical and Chemical Industries, Cairo, Egypt). Other materials and solvents were of analytical grade and used without further purification.

\section{Equipment}

Vacuum drier, Type SPT-200 (Zeamil Horizont Co., Poland), Digital sensitive electric balance (Metler, Switzerland), Double beam spectrophotometer, UV-1601 (Shimadzu Co., Japan), Vibrational sieve shaker, Rx-86-1 (Cole Palmer Instrument Co., USA), pH meter Ama digital (Ama Co., Germany), Dissolution test apparatus, SR II 6 flask (Hanson Co., USA), Infrared spectrophotometer, IR-476 (Shimadzu Co., Japan), Differential scanning calorimeter, DSC-50, equipped with a computerized data station (Shimadzu Co., Japan). and X-ray diffractometer (Philips Co., Netherlands).

\section{Methods \\ Preparation of the loaded mixtures}

The different used carriers were passed from $200 \mu \mathrm{m}$ sieves and retained on $125 \mu \mathrm{m}$ sieves. Florite $\mathrm{R}$ was dried in vacuum at 0.1
$\mathrm{mmHg}$ and temperature of $120^{\circ}$ for $3 \mathrm{hr}$. Avicel PH 101 was dried in vacuum at $0.1 \mathrm{mmHg}$ and temperature of $70^{\circ}$ for $24 \mathrm{hr}$. Bentonite was used as received.

The loaded mixtures of naproxen with the used different carriers were prepared by solvent deposition method. ${ }^{14}$ The calculated amount of each adsorbent was added to the methanolic solution of naproxen to give the desired drug/adsorbent ratios. Adsorbate systems containing (2:1), (1:1) and (1:2) w/w drug/adsorbent ratios were prepared. Methanol was evaporated at room temperature and its full removal was carried out over anhydrous calcium chloride till constant weight. The samples were then scrapped and the particle size of the prepared mixtures was reduced to the initial size of the used adsorbents.

\section{Preparation of physical mixtures}

The physical mixtures of the drug and various investigated adsorbents in different drug/polymer ratios $(2: 1),(1: 1)$ and (1:2) were prepared by simple mixing for five minutes using mortar and pestle avoiding any grinding effect. $^{14}$

\section{Characterization of the prepared adsorbate and physical mixtures}

Assay of drug content to evaluate the uniformity of samples

Known amounts of the prepared mixtures were dissolved in ethanol and then the drug content was evaluated spectrophotometrically at $272 \mathrm{~nm}$. Only those mixtures containing 100 $\pm 5 \%$ of the required naproxen were used for further studies. ${ }^{20}$

\section{Differential ultraviolet absorption study}

A $1 \%$ solution of each adsorbent in citrate buffer of $\mathrm{pH} 5.03$ were scanned using citrate buffer as a blank. Also solutions containing the same concentration of naproxen were again scanned in the presence of each of the previous adsorbents using citrate buffer as a blank. This was done in order to investigate the posibility of interference which may occurred between naproxen and the selected adsorbents.

\section{In-vitro dissolution studies}

The dissolution of the drug from the different prepared adsorbate using different adsorbents (Florite R, Avicel PH 101 and 
Bentonite) in different drug/adsorbent ratios was carried out using USP paddle dissolution apparatus. The dissolution medium was $500 \mathrm{ml}$ of citrate buffer $\mathrm{pH} 5.03$ maintained at $37 \pm 3^{\circ}$ and stirred at $60 \mathrm{rpm}$. Aliquots of $5 \mathrm{ml}$ of each sample were withdrawn at specified time intervals and replaced by an equal volume of the same dissolution medium kept at $37^{\circ}$. The amount of naproxen dissolved were determined spectrophotometrically at $272 \mathrm{~nm}$ using the dissolution medium as blank. Each experiment was performed twice and the mean was calculated in each case. The cummulative amount of drug was calculated to compensate for the previously withdrawn samples in the dissolution studies.

\section{Infrared spectroscopy}

IR spectra of some investigated samples (Florite R, Avicel PH 101 and Bentonite) were obtained by using an IR spectrophotometer through compressing the sample with $\mathrm{KBr}$ as following: Samples of 1-2 mg were mixed with potassium bromide, compressed into discs in compressor unit under vacuum then scanned from 4000 to $600 \mathrm{~cm}^{-1}$ with an empty pellet holder as a reference.

\section{Differential scanning calorimetry}

DSC was performed using DSC-50 Shimadzu instrument under the following conditions:

Sample weight range of 4-8 $\mathrm{mg}$, heating rate of $10 \% \mathrm{~min}, \mathrm{~N}_{2}$ purge rate of $40 \mathrm{ml} / \mathrm{min}$ using aluminum pan hermetically sealed. The instrument was calibrated for temperature and energy with pure indium (99.999\%, melting point $156.6^{\circ}$ and transition energy $28.45 \mathrm{~J} / \mathrm{g}$ ). Thermal analysis was carried out using TA 50 PC system with Shimadzu software program.

\section{X-ray diffractometry}

The X-ray diffraction patterns of the selected samples were obtained using a computer Philips operating in two modes using $\mathrm{CuK} \alpha$ radiation. $\mathrm{A} \mathrm{Cu}$ target tube operated at a voltage of $40 \mathrm{KV}$ and a current of $40 \mathrm{~mA}$ and a single crystal graphite monochromator were employed. An attached microprocessor utilizes a special software program to analyze peak position and intensities. Standard polycrystalline silicon was used to calibrate the equipment.

\section{RESULTS AND DISCUSSION}

It was found that, the adsorbents used in this study showed no absorption for the specified $\lambda_{\max }$. The scanning of naproxen in the presence of different adsorbents also reveald that peak positions and absorbance values at the used wave lengthes didn't change in the presence of any of selected adsorbents. It was concluded that, The selected adsorbents didn't interfere with the spectrophotometric assay of the drug in the investigated solutions.

The dissolution behavior of naproxen from the loaded mixtures, physical mixtures and plain drug are graphically represented by Figures (1-3). It is obvious that, the rate of dissolution of naproxen varied with the nature of the surface material component used for preparing the loaded mixture.

Generally, the dissolution rate of the drug from loaded mixtures is higher than physical mixtures and both are higher than the plain drug.

The dissolution rate profiles of naproxen / Florite $\mathrm{R}$ systems which are represented by Figure (1), exhibited the highest dissolution characteristics. However, the drug dissolution regarding adsorbate $(1: 2)$ drug/Florite ratio is higher than that of $(2: 1)$ and $(1: 1)$ ratios. $100 \%$ of the drug was released from adsorbate of $(1: 2)$ and (1:1) ratios at 45 and 75 minuets respectively. But in case of $(2: 1)$ ratio, the full dissolution was not obtained till the end of the experiment. The higher dissolution rate of naproxen regarding those mixtures loaded with porous calcium silicates could be explained in the view of the rapid desorption of the physically adsorbed drug molecules which were released simultaneously onto the dissolution medium. The dissolution mechanism is therefore different from that of plain drug where dissolution occurred from the surface of drug crystals according to the concentration gradient. ${ }^{21}$

Figure (2) showed the dissolution behavior of naproxen/Avicel PH 101 systems which exhibited similar results as in case of Florite R but with a lesser extent. Similar results were reported by El-Sayed et al. ${ }^{17}$ who studied the effect of porous silica and microcrystalline cellulose on the dissolution rate of phenytoin. The obtained results proved 
that the effect of Florite $\mathrm{R}$ is superior as compared with Avicel.

Regarding the dissolution behavior of naproxen / Bentonite systems graphically represented by Figure (3), it could be concluded that, the increase in the concentration of adsorbent leads to an increase in the in dissolution rate of the drug, also loaded mixtures exhibited a higher dissolution rate compared with the physical mixtures or the drug.

Table (1) showed the analysis of dissolution data by determination of relative dissolution ratio (RDR) and dissolution half lives $\left(\mathrm{T}_{50 \%}\right)$ for plain drug and different naproxen/adsorbent systems of (1:2) ratio. It is clear from the obtained results that, the increase in the drug dissolution rate was much higher in the first $5 \mathrm{~min}$. of the experiment as reached to about 17 times the dissolution rate of plain drug in case of loaded mixture with Florite $\mathrm{R}$ (1:2) ratio. Also $\mathrm{T}_{50 \%}$ of plain naproxen was attained after $75 \mathrm{~min}$. but in case of naproxen/Florite $\mathrm{R}$ loaded mixture $\mathrm{T}_{50 \%}$ was attained after lass than $5 \mathrm{~min}$.

The increased dissolution rate of naproxen from physical mixtures may be due to the deaggregation of naproxen clumps achieved by the carriers in the dissolution medium.

The enhancement of the dissolution rate of the drug from loaded mixtures may be due to:

- An extreme reduction in particle size of drug in accordance to its adsorption onto the surface of adsorbent leading to a higher surface area that facing the dissolution medium and subsequently increasing wettability. $^{14}$

- The physical interaction between the drug and polymer through hydrogen bonding and Vander-Waal's forces are responsible for adsorption of drugs onto the surfaces of adsorbents and accounted for rapid desorption of drugs from adsorbent surfaces. $^{22,23}$ This interaction can be explored using IR spectroscopy.

- Also the enhancement in dissolution rate may be due to the conversion of the drug from the crystalline to amorphous state which can be confirmed mostly by both Xray and DSC analysis. ${ }^{14}$

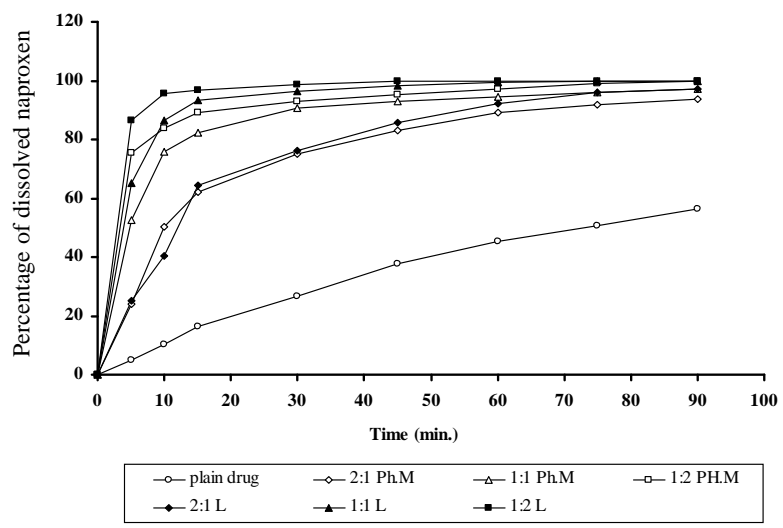

Fig. 1: Dissolution profiles of naproxen from Florite $\mathrm{R}$ systems in different drug / adsorbent ratios.

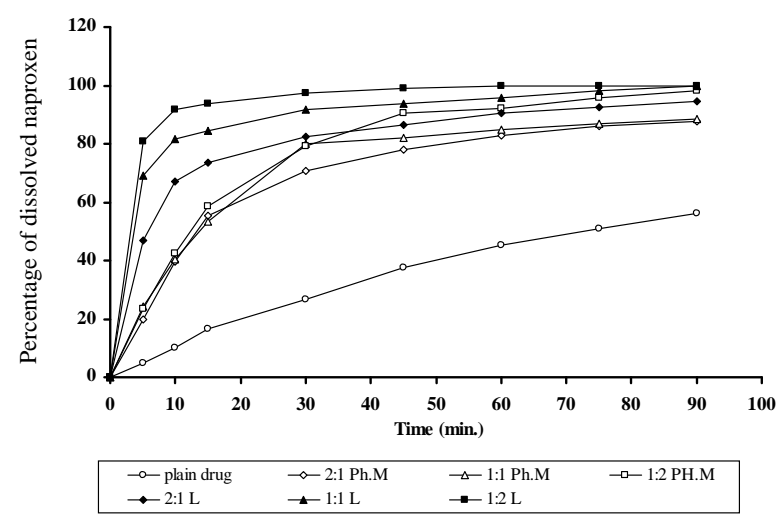

Fig. 2: Dissolution profiles of naproxen from Avicel PH 101 systems in different drug/ adsorbent ratios

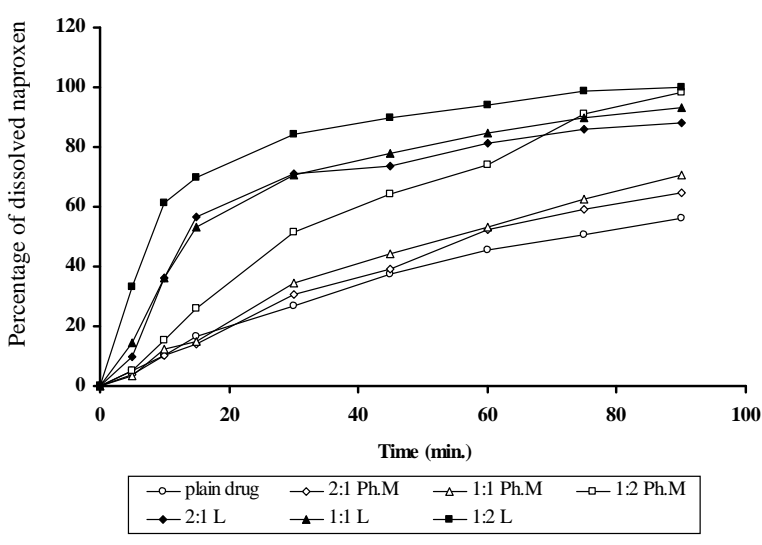

Fig. 3: Dissolution profiles of naproxen from Bentonite systems in different drug/ adsorbent ratios. 
Table 1: $\mathrm{T}_{50 \%}$ and relative dissolution ratio (RDR) values for different naproxen/adsorebent systems of (1:2) ratio.

\begin{tabular}{|c|c|c|c|c|c||}
\hline \multirow{2}{*}{ System } & \multirow{2}{*}{$\begin{array}{c}\mathrm{T}_{50 \%} \\
\text { (min.) }\end{array}$} & \multicolumn{4}{|c|}{ RDR values at time (min.) } \\
\cline { 3 - 6 } & 75 & 1.0 & 1.0 & 1.0 & 1.0 \\
\hline Plain Drug & $<5$ & 17.28 & 9.38 & 3.69 & 2.2 \\
\hline $\begin{array}{c}\text { Drug/Florite } \\
\text { adsorbate }\end{array}$ & $<5$ & 15.06 & 8.20 & 3.48 & 2.13 \\
\hline $\begin{array}{c}\text { Drug/Florite } \\
\text { Ph.Mix. }\end{array}$ & $<5$ & 16.14 & 9 & 3.60 & 2.2 \\
\hline $\begin{array}{c}\text { Drug/Avicel } \\
\text { adsorbate }\end{array}$ & 12.8 & 4.7 & 4.15 & 2.95 & 2.02 \\
\hline $\begin{array}{c}\text { Drug/Avicel } \\
\text { Ph.Mix. }\end{array}$ & 8.2 & 6.64 & 6 & 3.14 & 2.07 \\
\hline $\begin{array}{c}\text { Drug/Bentonite } \\
\text { adsorbate }\end{array}$ & 30 & 1.02 & 151 & 1.92 & 1.62 \\
\hline $\begin{array}{c}\text { Drug/Bentonite } \\
\text { Ph.Mix. }\end{array}$ & \multicolumn{4}{|l}{} \\
\hline
\end{tabular}

In an attempt to elucidate the physicochemical properties of the prepared systems, infrared absorption spectra for plain drug, some selected adsorbents (Florite R, Avicel PH 101 and Bentonite) and the prepared systems were carried out and represented by Figures (4-6).

The IR spectrum of naproxen was characterized by bands at $1726 \mathrm{~cm}^{-1}$ corresponding to the carboxylic $(\mathrm{C}=\mathrm{O})$ group and another band at $3480 \mathrm{~cm}^{-1}$ corresponding to the $(\mathrm{O}-\mathrm{H})$ stretching.

The IR spectra of (1:2) drug/Florite $R$ systems were investigated and illustrated in Figure 4, Florite R spectrum is characterized by a complete absence of infrared absorption bands due to its organic nature (porous calcium silicate). The infrared absorption spectrum of drug/Florite $\mathrm{R}$ physical mixture (trace $\mathrm{C}$ in Figure 4) showed that, the drug bands are still present at the same position but with low intensity. Whereas in case of loaded mixtures, the band corresponding to $(\mathrm{C}=\mathrm{O})$ stretching of drug is completely disappeared in both two ratios, (trace D in Figure 4).

This may be due to the adsorption of the drug molecules on the surface of Florite $R$ which had high adsorption capacity owing to its large surface area and well clearly point to the possibility of hydrogen bonding between the drug and Florite R.

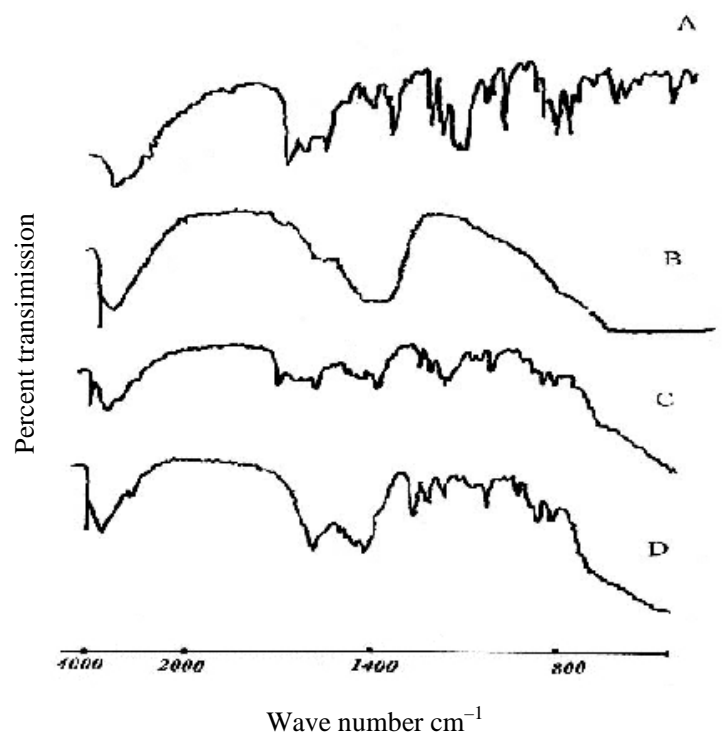

Fig. 4: The IR Spectra of (1:2) drug / Florite R systems where:

A- Plain drug

B- Adsorbent

C- Physical mixture and

D- Adsorbate mixture 
Figure (5) shows the IR absorption spectra of drug/Avicel PH 101 in (1:2) ratio systems. Regarding both physical and loaded mixture, the characteristic peaks of the drug are still present at the same area as the plain drug but with an apparent reduction in the intensity, confirming the absence of any suspected interaction between the drug and Avicel $\mathrm{PH}$ 101.

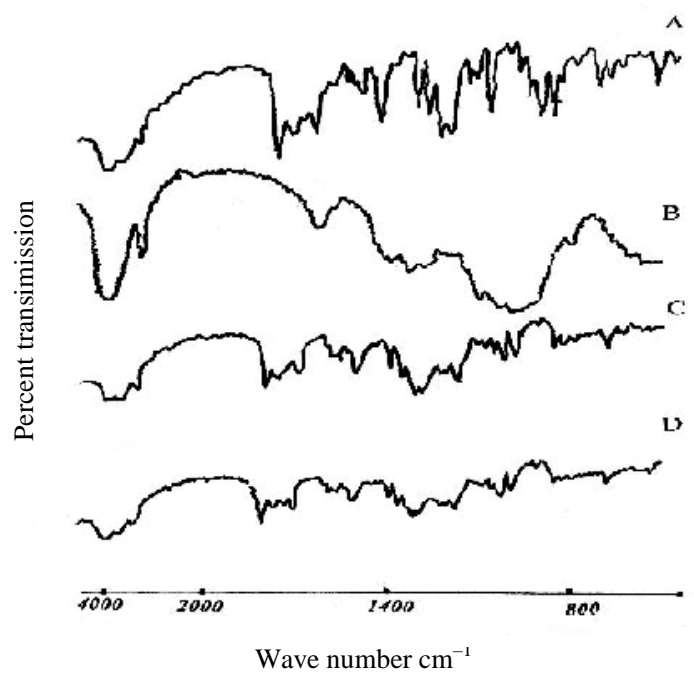

Fig. 5: The IR Spectra of (1:2) drug / Avicel PH101 systems where:

A- Plain drug

B- Adsorbent

C- Physical mixture and

D- Adsorbate mixture

The same results were also obtained upon handling with naproxen/Bentonite physical mixture and loaded mixture as illustrated by Figure (6).

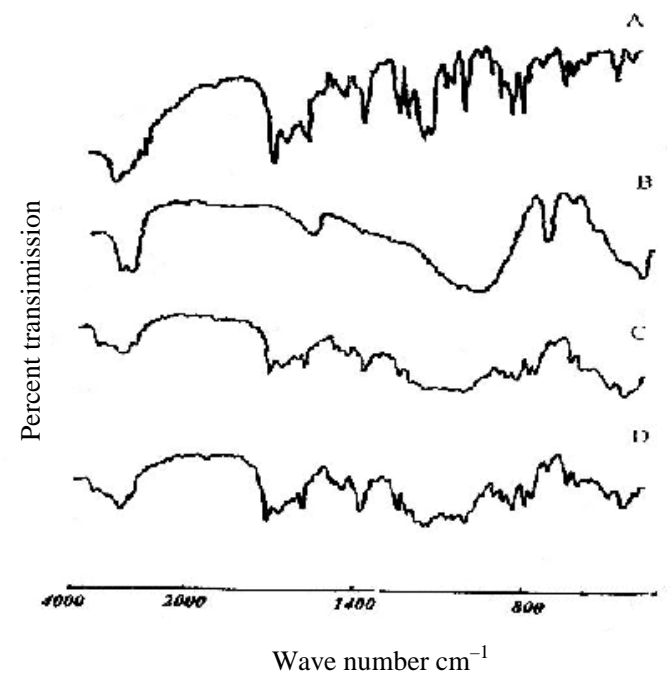

Fig. 6: The IR Spectra of (1:2) drug / Bentonite systems where:

A- Plain drug

B- Adsorbent

C- Physical mixture and

D- Adsorbate mixture
According to the obtained results regarding the IR spectroscopic studies of physical and loaded mixtures of the selected adsorbents it can be concluded that, there was not an obvious interaction between the drug and the investigated adsorbents (Avicel PH 101 and Bentonite). whereas, in case of drug/Florite $\mathrm{R}$ loaded mixture, hydrogen bonding might be formed between the drug and the hydroxyl groups on the adsorbent surfaces. Similar result were obtained when ledocaine was adsorbed on Florite R. ${ }^{24}$

DSC studies were performed in order to get a further evidence regarding any possible interaction of naproxen with the selected adsorbents according to appearance, shift or disappearance of endothermic or exothermic peaks and/or variation of the corresponding enthalpy. ${ }^{25}$

Thermograms of naproxen, selected adsorbents, physical mixtures and loaded mixtures were shown in Figures (7-9).

The DSC chart of the drug which depicted in (Figures 7-9, trace A), exhibited a sharp endothermic peak at $155.6^{\circ}$ with thaw temperature at $151^{\circ}$ and $\Delta \mathrm{H}$ of $-106.8 \mathrm{~J} / \mathrm{g}$ at scanning rate of $10^{\circ} / \mathrm{min}$. Figure (7), shows the thermograms of drug/Florite R systems in (1:1) and (1:2) ratios and also the individual components. The DSC curve of Florite R is characterized by absence of peaks within the temperature range employed $\left(30-200^{\circ}\right)$, (trace B).

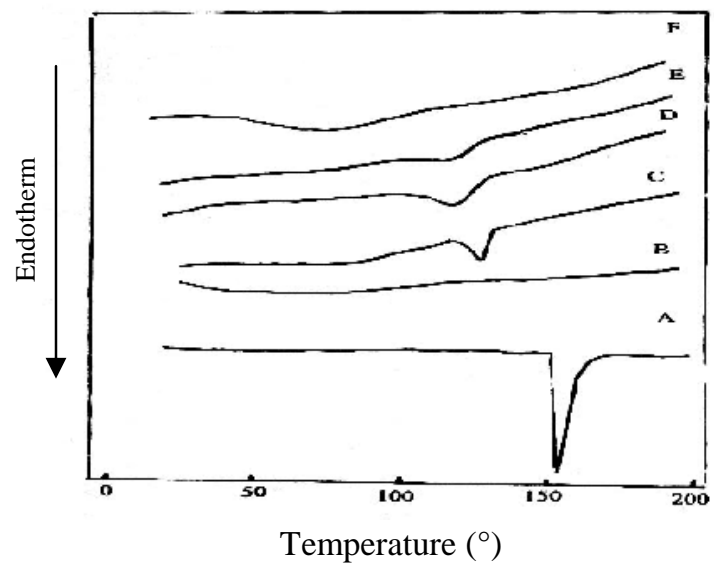

Fig. 7: DSC thermograms of naproxen/Florite R systems where:
A- Plain drug
B- Plain Adsorbent
C- $1: 1$, drug/adsorbent physical mixture
D- 1:2, drug/adsorbent physical mixture
E- 1:1, drug/adsorbent loaded mixture
F- 1:2, drug/adsorbent loaded mixture 
The thermograms of physical mixtures show the same drug characteristic peak but with low intensity (trace C\&D in Figure 7). Also regarding drug/Florite $\mathrm{R}$ loaded mixture of (1:1) ratio, small broad peak still present corresponding to the endothermic peak of the drug but with low intensity and little shift to a lower degree of temperature. (Figure 7, trace E). Increasing the concentration of Florite $\mathrm{R}$ in loaded mixture to (1:2) ratio accompanied by complete disappearance of any characteristic peak, indicating complete transformation of drug from crystalline to amorphous form at this ratio, (Figure 7, trace F).

DSC tracing of drug/Avicel PH 101 in (1:2) ratio loaded mixture, physical mixture and the individual components are depicted in Figure (8). The DSC chart of Avicel PH 101 (Figure 8, trace B) exhibited a shallow endothermic peaks at approximately $90^{\circ}$ which corresponds to the temperature of water evaporation. In case of physical mixture (trace C) it showed endothermic peak corresponding to drug but with little reduction in the intensity. In case of loaded mixture (trace D), the melting endothermic peak of the drug was greatly reduced and appears as a broad peak with little shifting. Again, transformation of drug to amorphous state could be the reason for the reduction of the intensity of the drug melting endotherm.

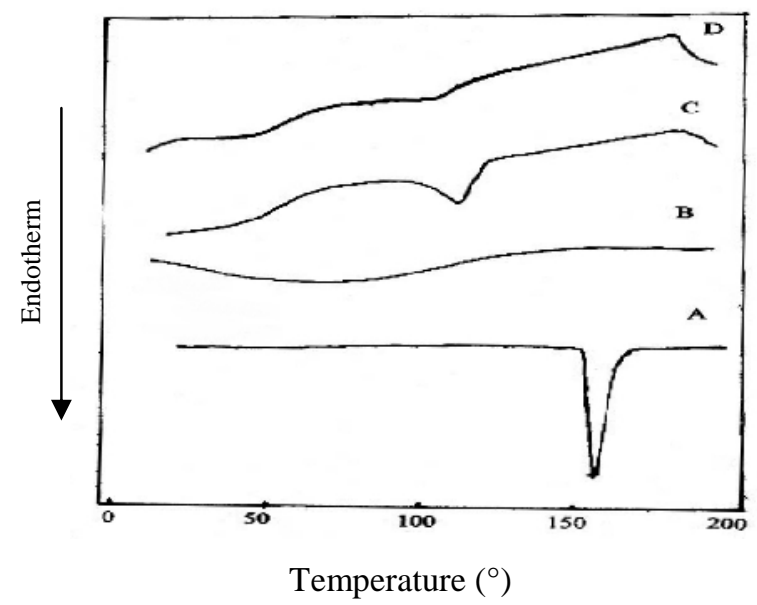

Fig. 8: DSC thermograms of (1:2) drug / Avicel PH 101 systems where:
A- Plain drug
B- Adsorbent
C- Physical mixture and
D- Adsorbate mixture

Regarding DSC thermograms of naproxen/Bentonite (1:2) ratio prepared systems (Figure 9), it is clear that, the endothermic peak of the drug is still present in both physical mixture and loaded mixture but with minute change, whereas the apparent shifting to the lower temperature was indicating a weak or no interaction between the drug and carrier, which confirms the results obtained by IR studies.

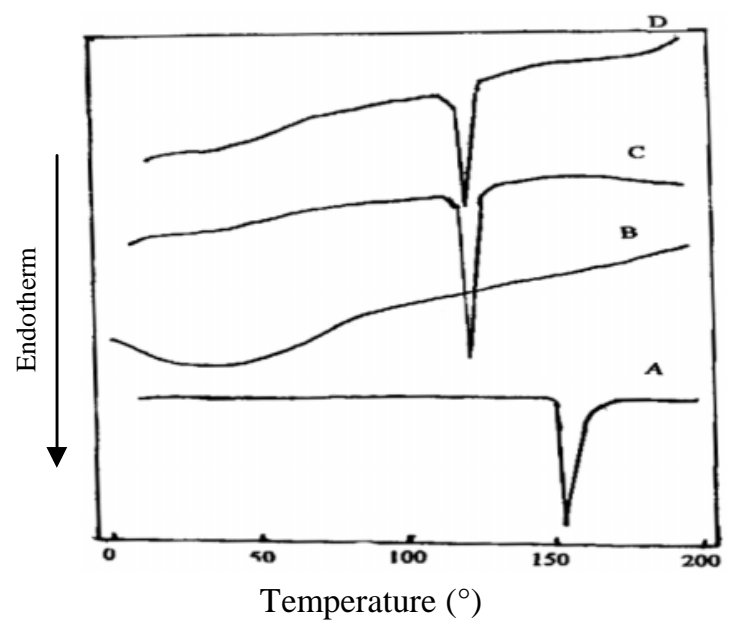

Fig. 9: DSC thermograms of (1:1) drug / Bentonite systems where:
A- Plain drug
B- Adsorbent
C- Physical mixture and
D- Adsorbate mixture

From these results it could be concluded that, adsorption of naproxen on the selected adsorbents results in the transformation of the drug from crystalline to amorphous state (especially in case of Florite $\mathrm{R}(1: 2)$ ratio) which has a tendency to induce this transformation greater than that of other carriers. Similar results were obtained by ElSayed et al. ${ }^{17}$ who studied the effect of porous silica and microcrystaline cellulose as carriers for phenytoin. The results revealed that Florite $\mathrm{R}$ was able to induce transformation of phenytoin from crystalline to amorphous state compared with Avicel.

In addition, the transformation of the drug depends to a large extent on the ratio of the adsorbent to the drug in the mixture. Hence the higher the ratio of adsorbent to the drug in the mixture, the higher the extent of the drug state transformation. These results are in agreement with those obtained by Safwat $^{26}$ and Co workers who studied the effect of porous silica on the physicochemical properties of nystatin. 
From the previous DSC studies, it is obvios that, non of the samples showed any major new peaks, hence it can be concluded that the used adsorbents are compatible with naproxen even when high concentrations of adsorbent were used.

X-ray Diffractometry technique was utilized to study the crystallographic nature of adsorbate mixture, physical mixture and plain drug. The major X-ray diffraction peaks of naproxen were observed at $2 \theta$ of $6.59,18.9$, $19.9,22.2, \quad 22.5$ and 28.3 with relative intensities of $100,65,48,92,59$, and 53 respectively.

The X-ray diffraction pattern of naproxen/Florite $\mathrm{R}$ and naproxen /Avicel $\mathrm{PH}$ 101 physical mixtures in (1:2) drug/adsorbent ratio, showed smaller characteristic peaks than those of the plain drug but of reduced intensity as illustrated in (Figures 10-12, trace C).

In case of loaded mixture of naproxen /Avicel PH 101 in a ratio of $(1: 2)$ as represented by (Figure 10, trace D), it was found that, there was an incomplete transformation of the drug to the amorphous state accompanied by a slight reduction in the intensity of the characteristic peaks of naproxen, whereas the extent of reduction in the peak intensity in case of loaded mixture is higher than that of the corresponding physical mixture.

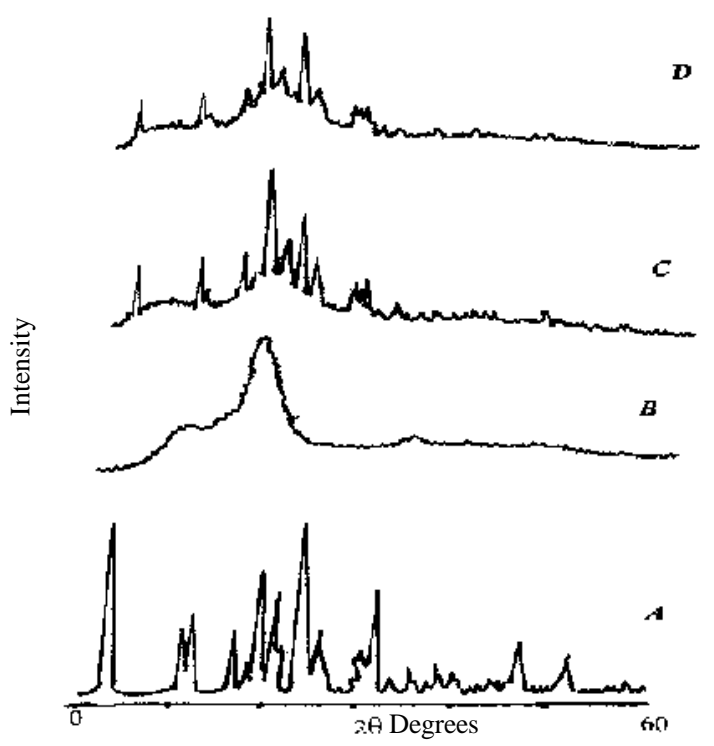

Fig. 10: X-ray diffraction patterns of (1:2) drug/ Avicel PH 101 systems where:

A- Plain drug

B- Adsorbent

C- Physical mixture and

D- Adsorbate mixture
Regarding the adsorbate composed of naproxen/Florite $\mathrm{R}$ in (1:2) ratio, as shown in (Figure 11, trace $\mathrm{D}$ ) one can observe that, the peaks corresponding to the drug have completely disappeared, whereas the drug/adsorbent loaded mixture (1:1) (Figure 12 , trace $\mathrm{D}$ ), exhibited the characteristic peaks of the drug but with a low intensity pattern.

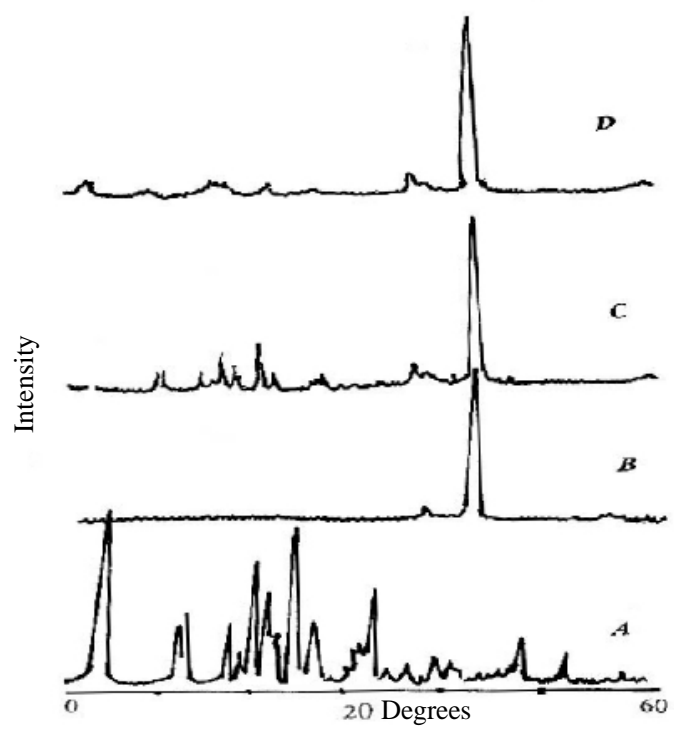

Fig. 11: X-ray diffraction patterns of (1:2) drug/ Florite R systems where:
A- Plain drug
B- Adsorbent
C- Physical mixture and
D- Adsorbate mixture

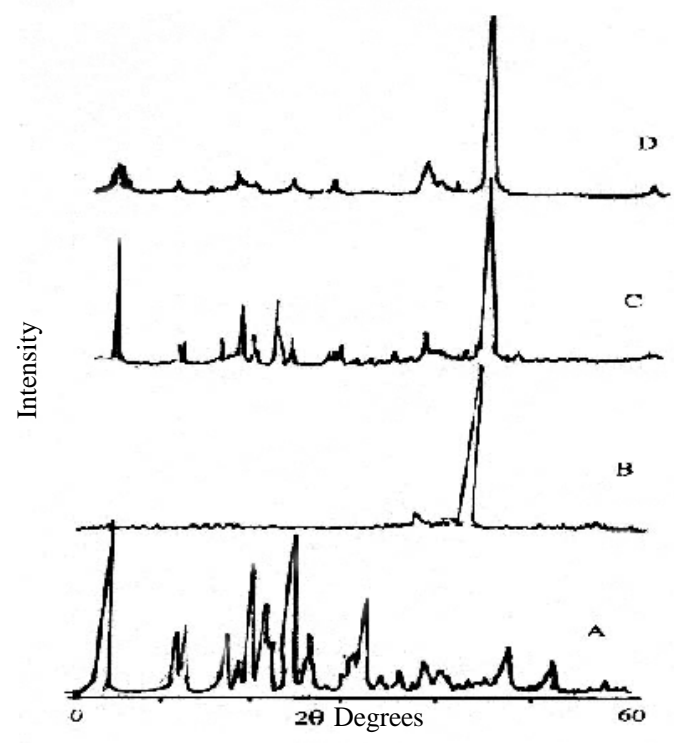

Fig. 12: X-ray diffraction patterns of (1:1) drug/ Florite R systems where:
A- Plain drug
B- Adsorbent
C- Physical mixture and
D- Adsorbate mixture 
It can be assumed from these results that loading of naproxen on porous silica resulted in its transformation to amorphous state (mixture containing 1:2 ratio) or a reduction of its crystallinity and incomplete transformation to the amorphous state (mixture containing 1:1 ratio).

The X-ray diffraction charts proved that, Florite $\mathrm{R}$ has the greatest ability as compared with other polymers, to induce the transformation of naproxen to the amorphous state using the ratio (1:2).

The results are in a good agreement with those obtained through investigation the effect of porous silica and microcrystalline cellulose as carriers on phenytoin. ${ }^{17} \mathrm{X}$-ray diffraction pattern indicated that, Florite $\mathrm{R}$ exhibited higher induction of transformation of drug to the amorphous state as compared with microcrystalline cellulose.

The possible mechanism of interaction between porous silica and crystalline drugs has been discussed by Narai et al. ${ }^{27}$ They have proposed that, when the crystalline drugs were mixed with porous powders, the drug molecules penetrated into the capillaries. These molecules have an adsorption rate larger than those colliding with flat surfaces, since the molecules experience great number of collision with walls in the capillary, thus the molecules would easily loose their kinetic energy during the collision and rapidly become adsorbed on the surface of porous powder.

The phase transformation of crystalline naproxen to the amorphous form in the loaded mixtures with porous silica was explained in the view of physical adsorption phenomena associated with drug-silinol group interaction within the inner pores of the silica matrix. Adsorption may take place via Vander Waal's forces between the silinol group in the silica and the drug. ${ }^{14}$

\section{REFERENCES}

1- D. C. Mankhous and J. L. Lach, J. Pharm. Sci., 61, 1430 (1972).

2- P. Sheen, V. K. Khetarpal, C. M. Cariola and C. E. Rowlings, Int. J. Pharm., 118, 221 (1995).

3- R. Nair, S. Gonen and S. W. Hoag, Int. J. Pharm., 240, 11 (2002).
4 Z. Naima, T. Siro, Gines-Dorado JuanManuel, C. Cantal and C. Rene, Eur. J. Pharm. Sci., 12, 395 (2001).

5- M. Moneghini, I. Kikic, D. Voinovich, B. Perissutti and J. Filipovic-Gricic, Int. J. Pharm., 222, 129 (2001).

6- A. Sheth and C. I. Jarowski, Drug Dev. Ind. Pharm., 16, 769 (1990).

7- Y. Nakai, Drug Dev. Ind. Pharm., 12, 1017 (1986).

8- S. A. Ibrahim, T. H. El-Faham, E. Hafez and F. A. Mohammed, Pharm. Ind., 53, 401 (1991).

9- G. V. Betageri and K. R. Makarala, Int. J. Pharm., 126,155 (1995).

10- M. A. Bayomi, K. A. Abanumay and A. A. Al-Angary. Int. J. Pharm., 243 (1-2) 107 (2002).

11- P. Mura, N. Zerrouk, M. T. Faucci, F. Maestrelli and C. Chemtob, Eur. J. Pharm. and Biopharm., 54 (2) 181 (2002).

12- E. Spamer, D. G. Muller, P. L. Wessels and J. P. Wenter, Eur. J. Pharm. Sci., 16 (4-5), 247 (2002).

13- S. M. Alsaidan, A. A. Alsughayer and A. G. Eshra, Drug Dev. Ind. Pharm., 24 (4), 389 (1998).

14- A. Shaker, Bull. Pharm. Sci., Assiut Univerisity, 20 (1), 1 (1997).

15- H. A. Koeleman, R. van zyl, N. Sleyn, B. Boneschans and H. S. Steyn, Drug Dev. Ind. Pharm., 16, 5 (1990).

16- R. Shivastava, S. R. Jian and S. G. Frank, J. Pharm. Sci., 74, 214 (1985).

17- A. M. El-Sayed, A. A. Shaker and A. A. Assi, STP Pharma Sci., 3 (4), 319 (1993).

18- S. L. Law and C. H. Chaing, Drug Dev. Ind. Pharm., 16, 137 (1990).

19- S. M. Safwat, A. S. Ali, M. O. Ahmed and I. Abdel-Sabour, Bull. Pharm. Sci., Assiut Univer., 17, 139 (1994).

20- M. Moneghini, I. Kikic, D. Voinovich, B. Perissuti and J. Flipovic-Grcic, I. J. Pharm., 222, 129-138 (2001).

21- A. S. Ali, Bull. Pharm. Sci., Asiut Univ., 20 (1) (1997).

22- H. Rupprecht, Control. Drug Deliv., Wissenschaftl, Verlagsgesell, Stuttgart, 197 (1987). 
23- H. Rupprecht, Topics in Pharmaceutical Science, El Servier/North Holand Biomedical Press, New York, 1981, pp. 443-460.

24- U.S. Abu Uwida, Master Thesis, a Fucalty of Pharmacy, Assuit Univ. (2002).

25- P. Mura, A. Manderioli, G. Bramanti, S. Furlenetto and S. Penzauti, Int. J. Pharm., 71, 119 (1992).
26- S. M. Safwat, A. S. Ali, M. O. Ahmed and I. Abdel-Sabour, Pharm. Ind. 57, 5 (1995).

27- Y. Narai, K., Yamamoto K. Terada and T., Oguchi, Procedings $4^{\text {th }}$. International conference on Pharmaceutical technology, II, Paris, 1986, p. 48. 